ISSN (Print): 2709-9636 | ISSN (Online): 2709-9644

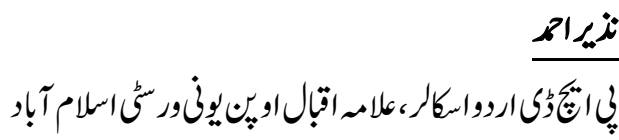

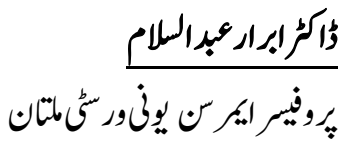

\title{
Nazir Ahmad
}

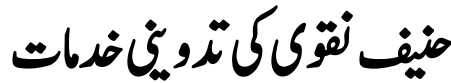

Scolar Ph.D Urdu, Allama Iqbal Open University, Islamabad.

\section{Dr. Abrar Abdul Salam}

Professor Emerson University Multan.

\section{Haneef Naqvi's Editins Services}

Hanif Naqvi was a very careful researcher and editor of Urdu Language and Literature. He re-edited 'Maasr-e-Ghalib' edited by Qazi Abdul Wadood. 'Tazkira e Shuray Sahswan' edited by Abu AlKamal Hakeem Syed Ejaz Ahmed Moijz and Hayat-Ul-Ulma, edited by Maulana Syed Abdul Baqi with great care and diligent. He has taken great care in these treatments and has added valuable corrections to the works of his predecessors. In view of his work, it can be claimed that he has made new directions in the Urdu compilation tradition. In addition, linguistic and spelling rules and regulations have been fully complied with in 'Maasr-e-Ghalib' , He has made important additions and corrections to Ghalib's habits, Ghalib's life, period of Ghalib and as well as linguistic spelling matters.

Keywords: Haneef $\mathcal{N a q v i ~ K i ~ T a d v e n i ~ K h i d m a t , ~ R e s e a r c h ~ A r t i c l e s . ~}$

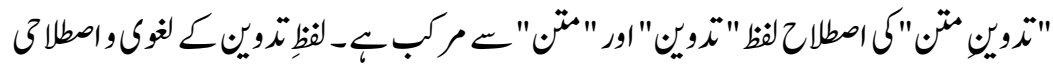

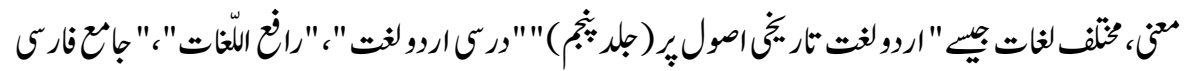

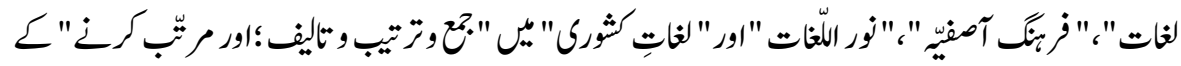

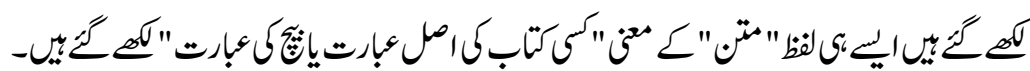


ISSN (Print): 2709-9636 | ISSN (Online): 2709-9644

Volume 2, 2021(Issue III, July to September)

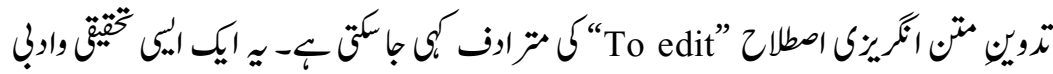

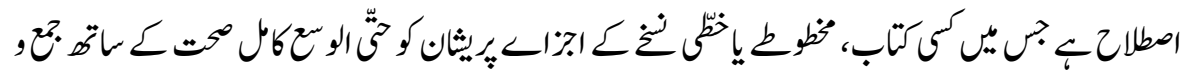

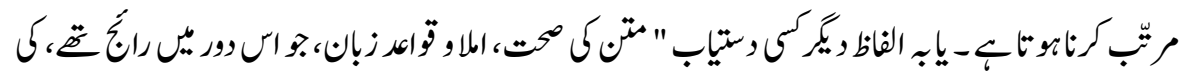

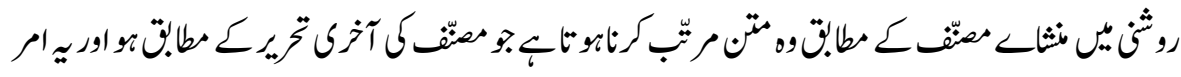

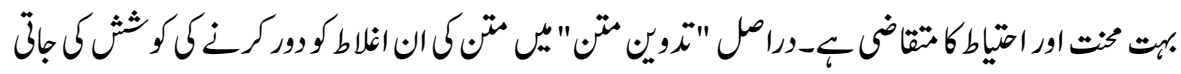

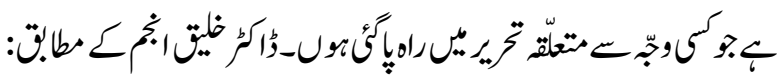

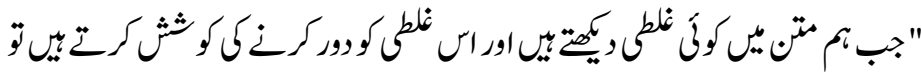

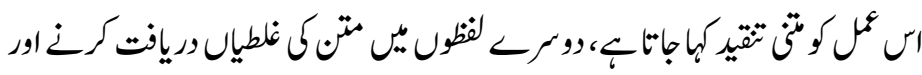

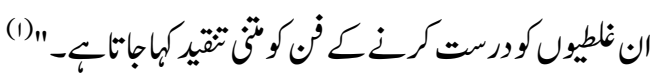

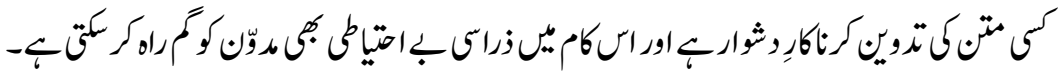

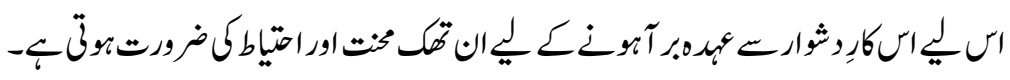

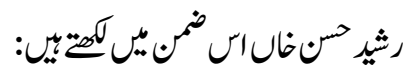

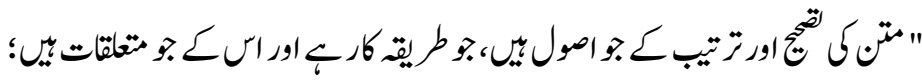

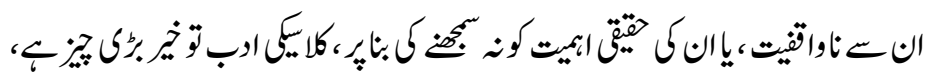

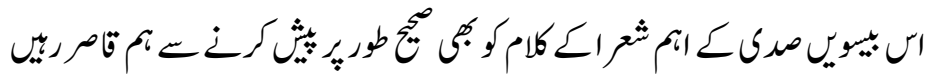
$(r) " \varepsilon$

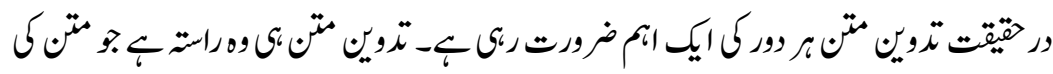

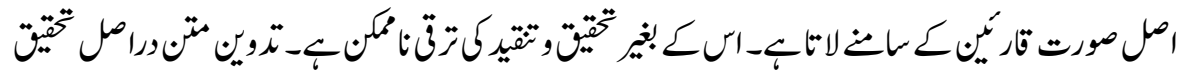

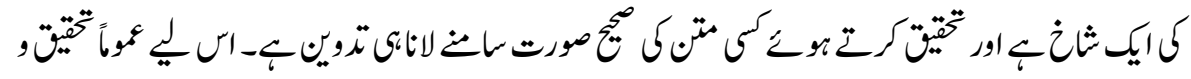

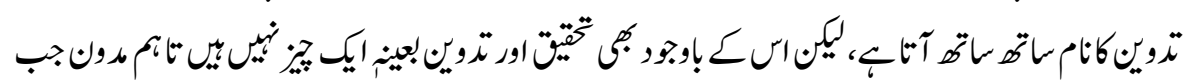

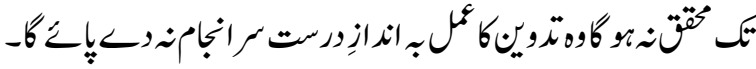

$$
\begin{aligned}
& \text { رشير حسنالك مطا.ت: }
\end{aligned}
$$


ISSN (Print): 2709-9636 | ISSN (Online): 2709-9644

Volume 2, 2021(Issue III, July to September)

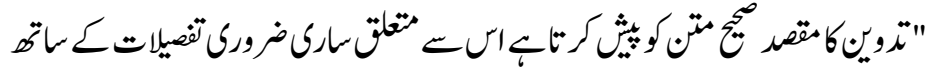

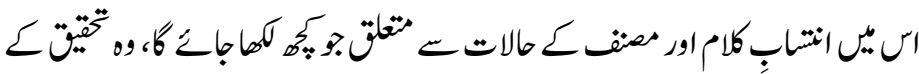

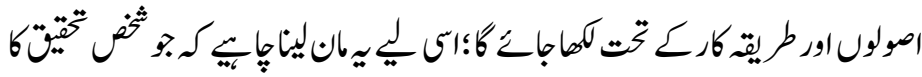

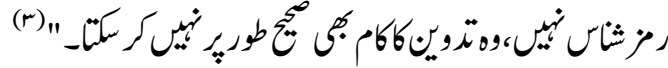

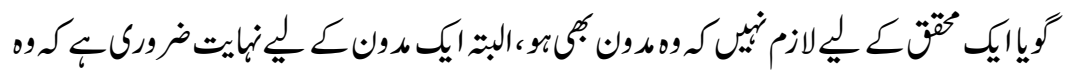

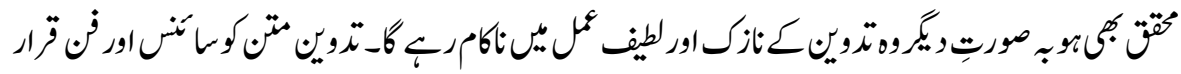

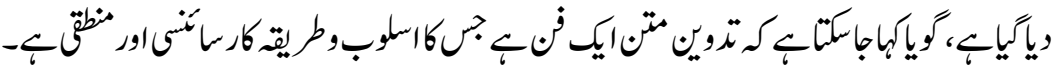

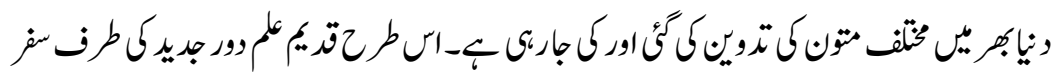

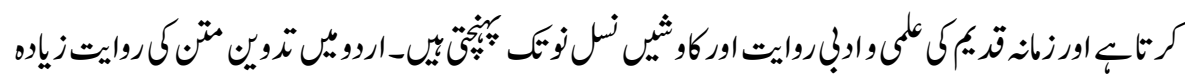

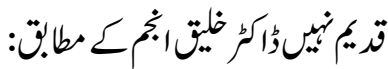

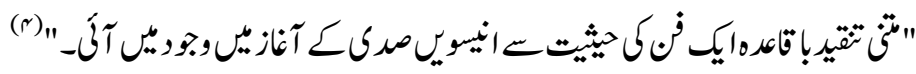

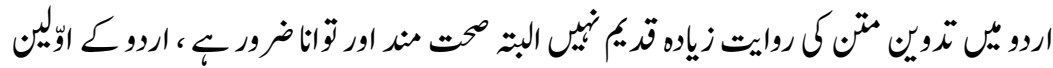

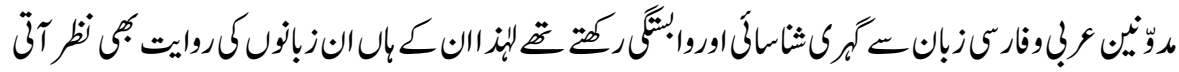

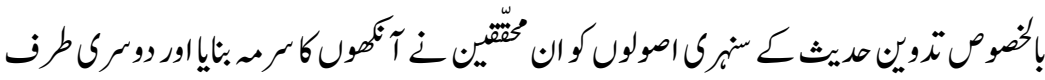

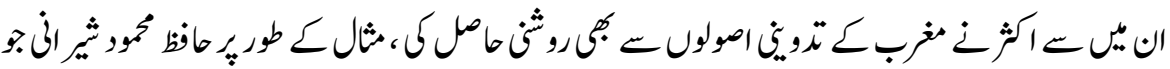

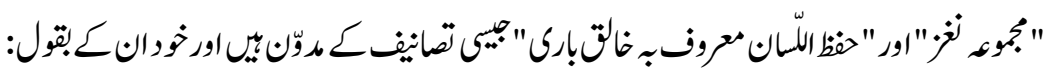

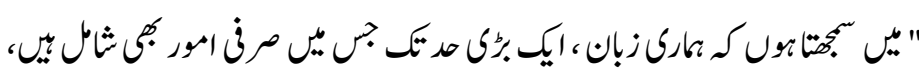

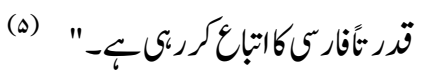

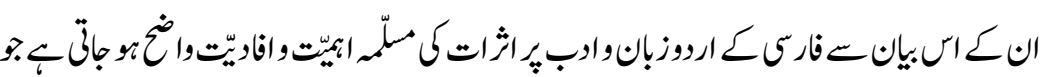

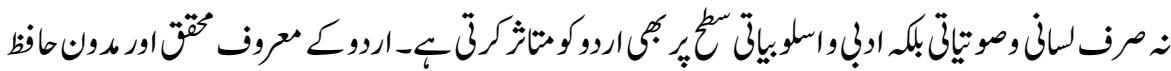

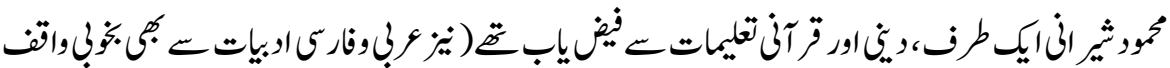

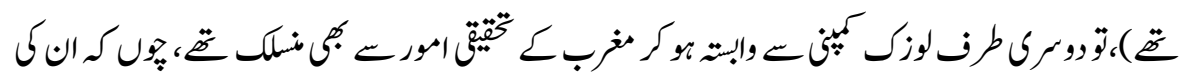


ISSN (Print): 2709-9636 | ISSN (Online): 2709-9644

Volume 2, 2021(Issue III, July to September)

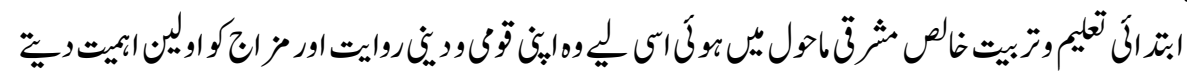

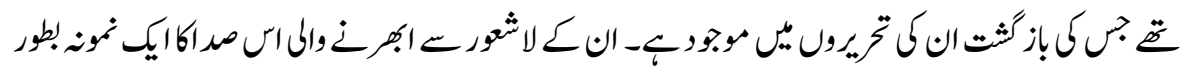
مثلئي

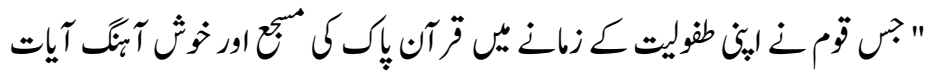

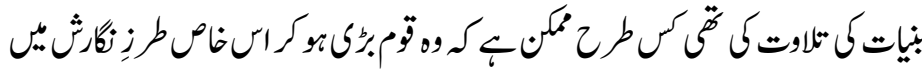

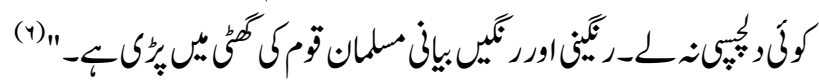

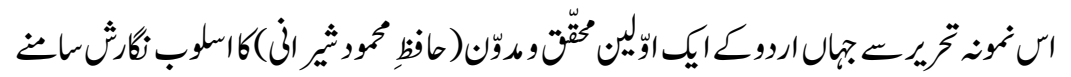

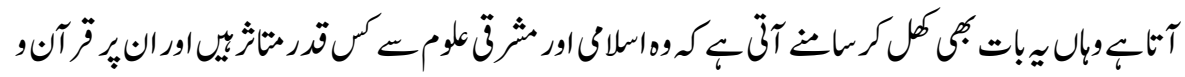

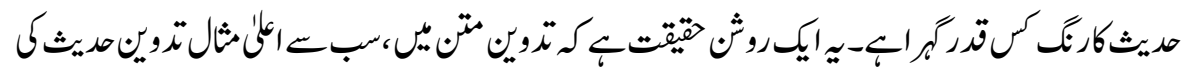

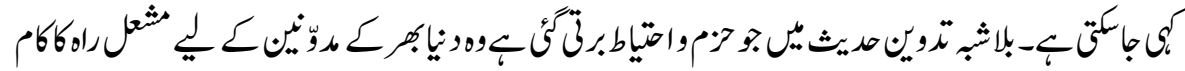

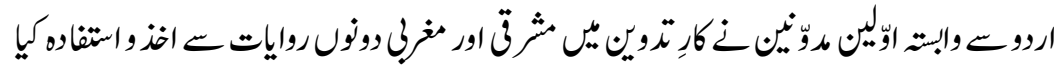

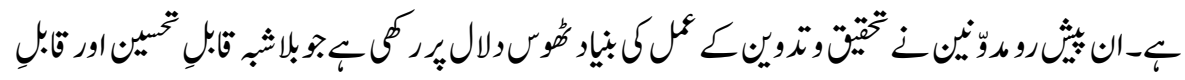

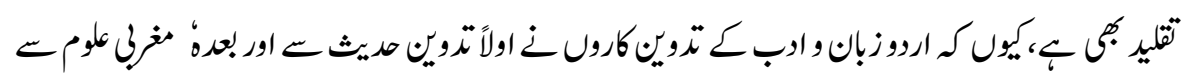

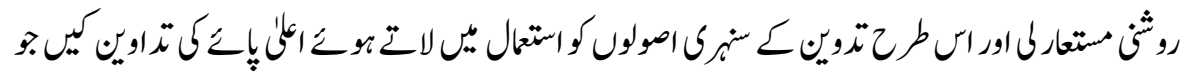

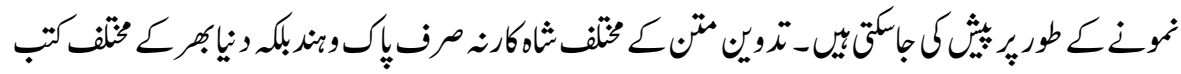

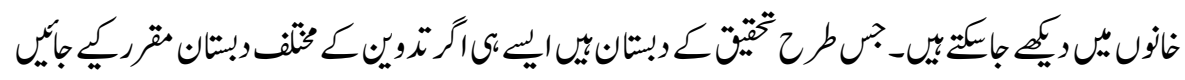

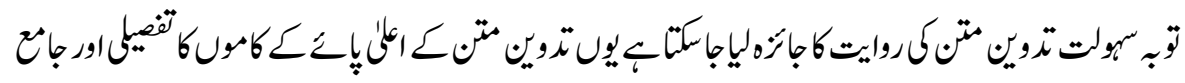

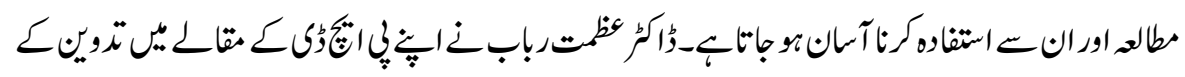

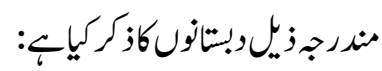

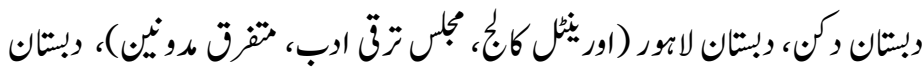

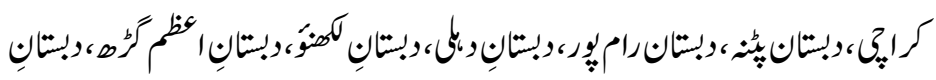

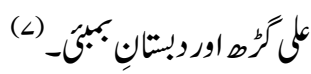


ISSN (Print): 2709-9636 | ISSN (Online): 2709-9644

Volume 2, 2021(Issue III, July to September)

انز تِيقي مجل

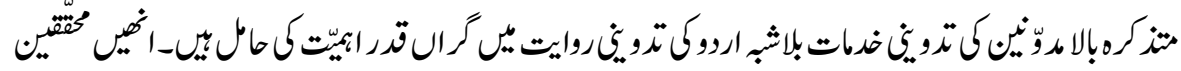

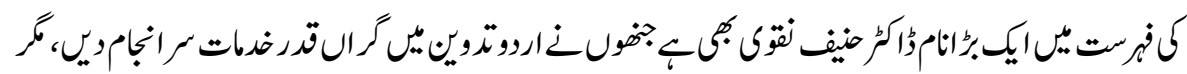

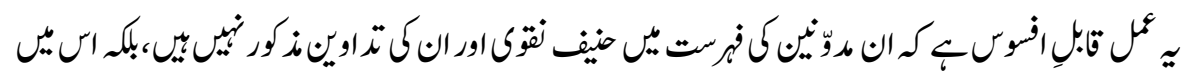

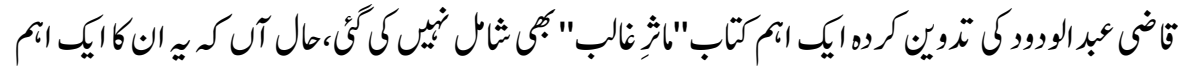

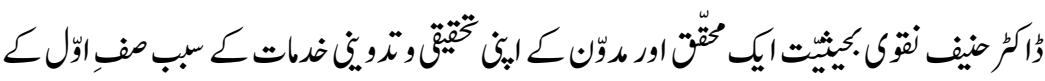

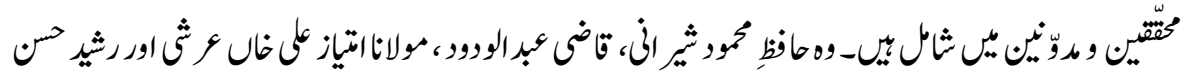

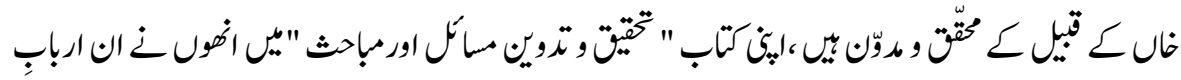

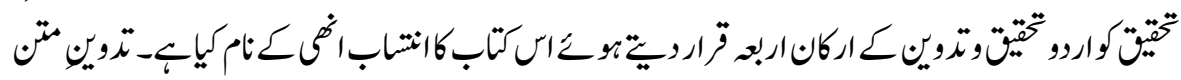

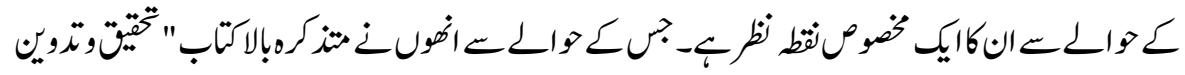

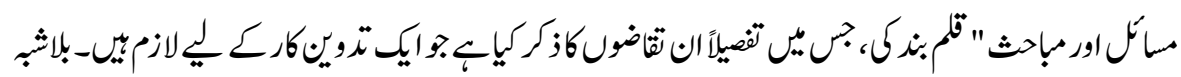

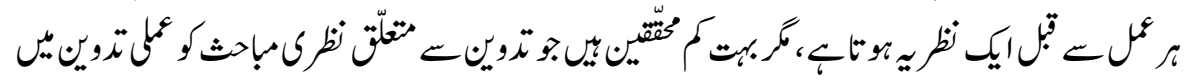

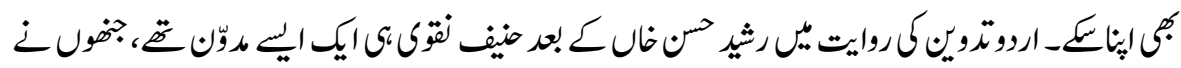

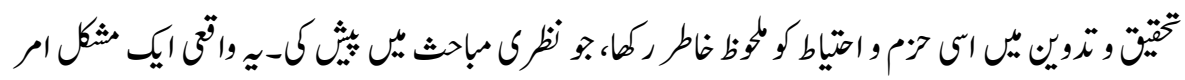

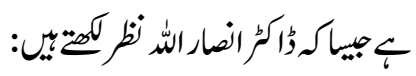

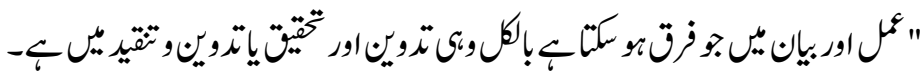

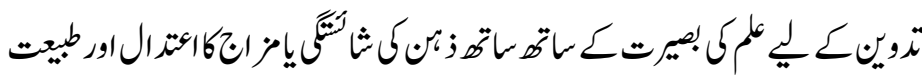

$$
\text { (1) }
$$

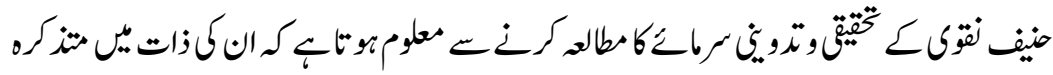

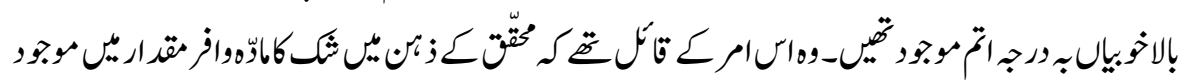

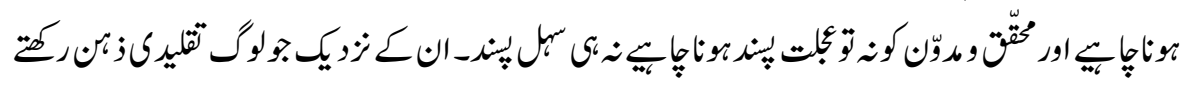

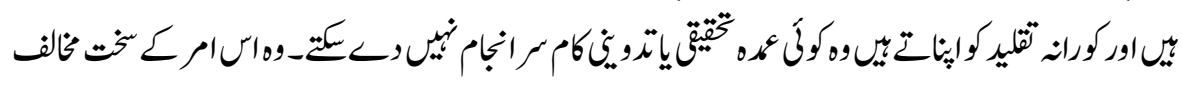

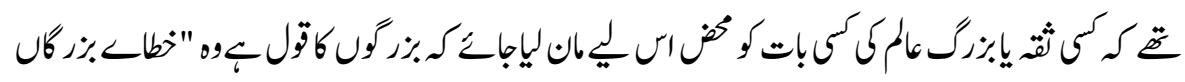


ISSN (Print): 2709-9636 | ISSN (Online): 2709-9644

Volume 2, 2021(Issue III, July to September)

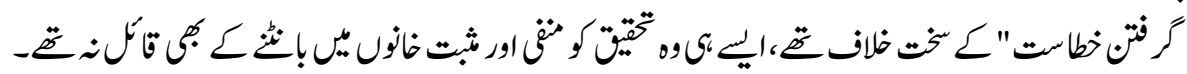

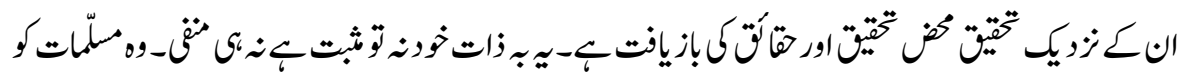

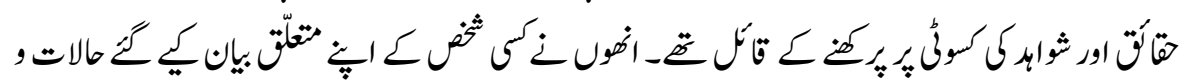

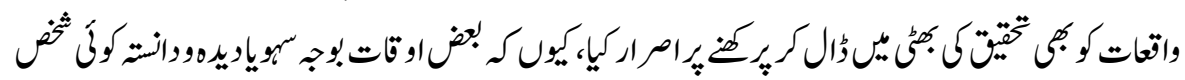

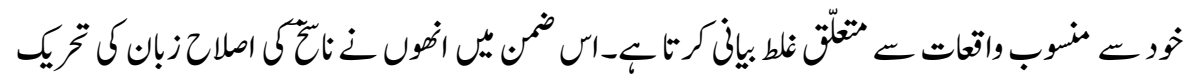

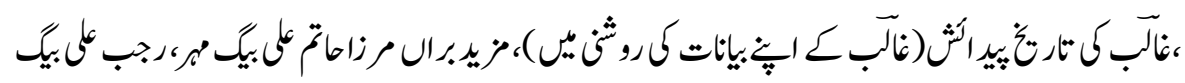

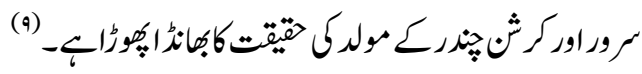

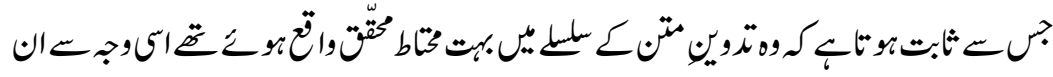

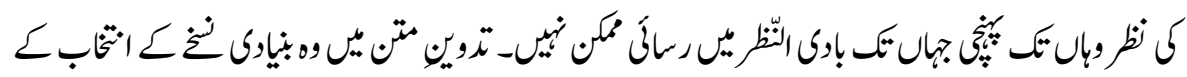

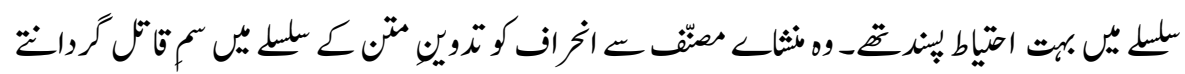

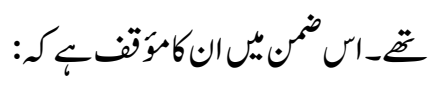

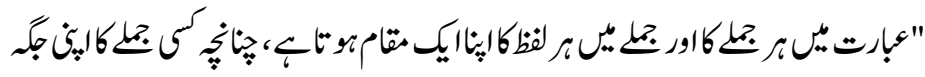

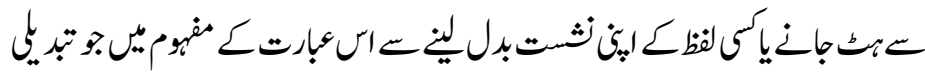

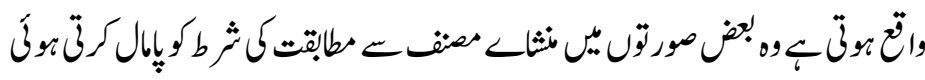

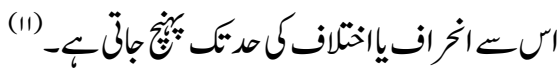

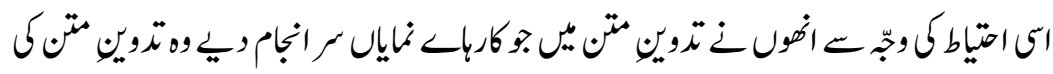

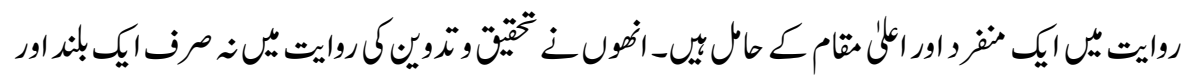

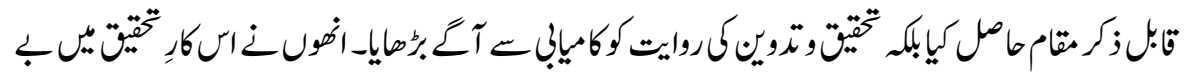

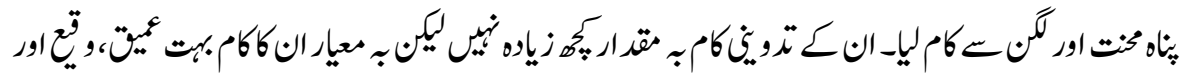

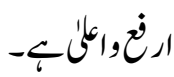

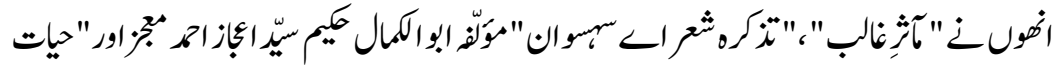

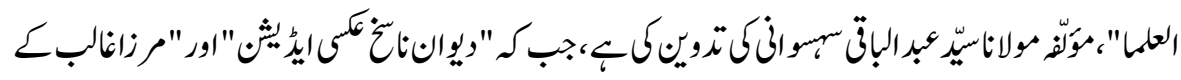


ISSN (Print): 2709-9636 | ISSN (Online): 2709-9644

Volume 2, 2021(Issue III, July to September)

انز تِيقي مجل

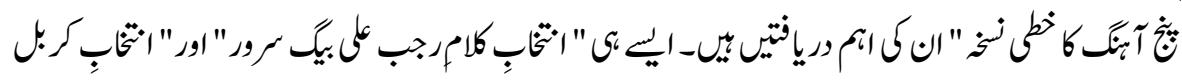

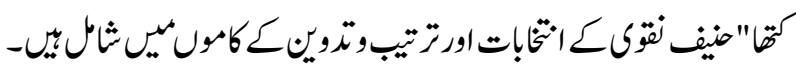

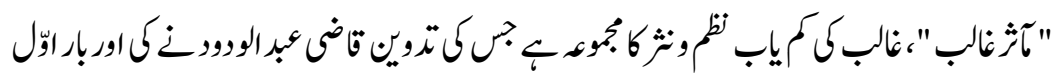

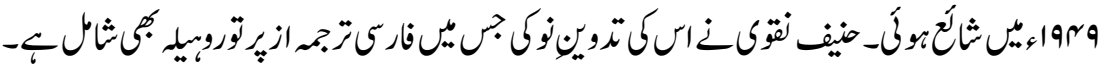

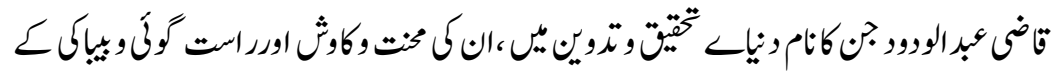

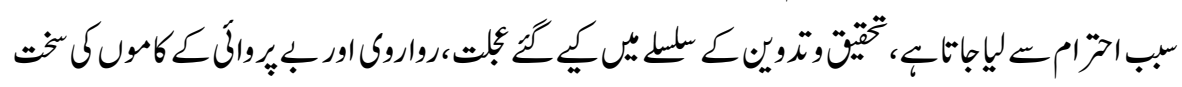

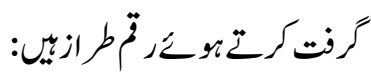

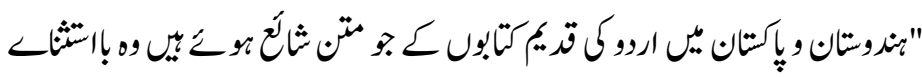

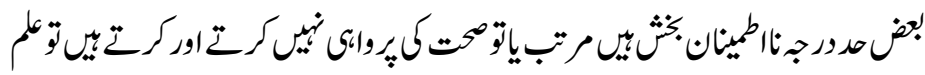

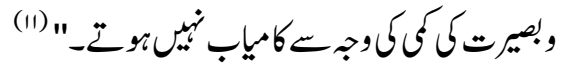

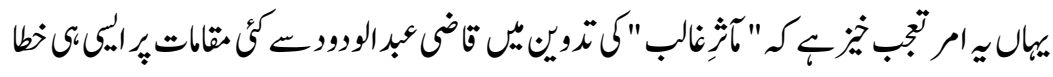

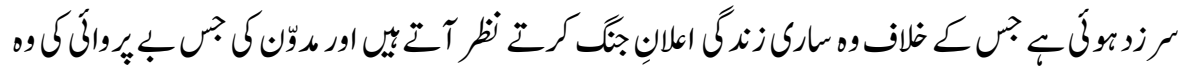

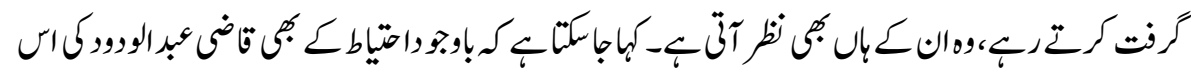

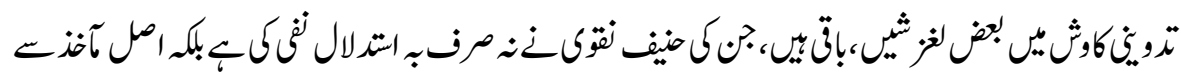

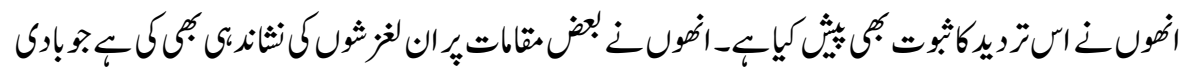

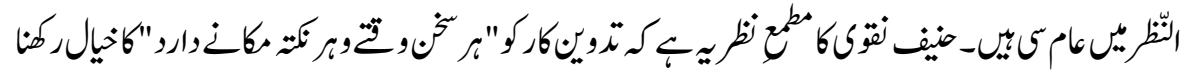

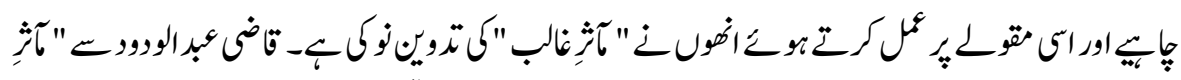

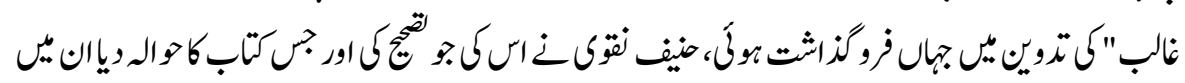

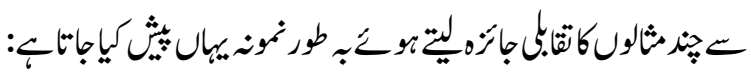
اضاف / لتجهيف نقوى

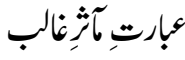
ا_اضتياركرك (طبعاول)
ا-سياحت اضتيارك

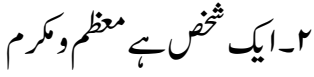

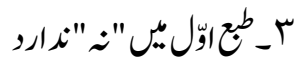

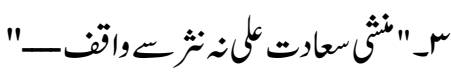

r-مترز (تاطعبرانورساكل متثقة) 
ISSN (Print): 2709-9636 | ISSN (Online): 2709-9644

Volume 2, 2021(Issue III, July to September)

اخذ تيقيق مجل

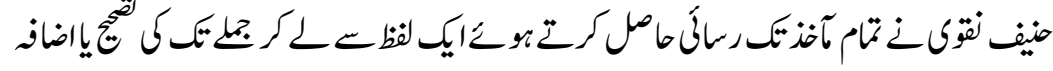

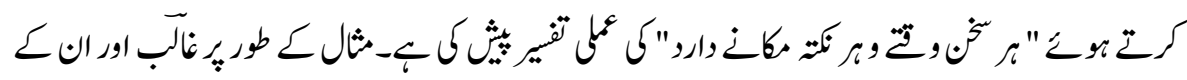

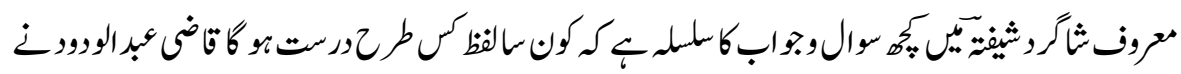

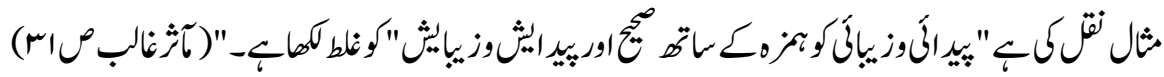

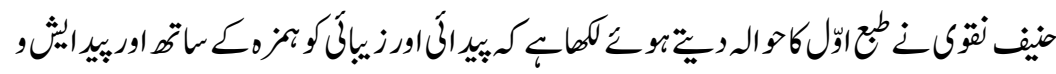

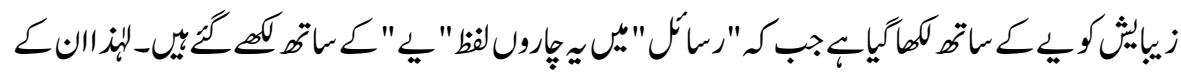

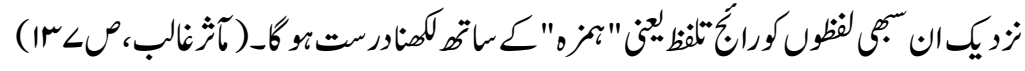

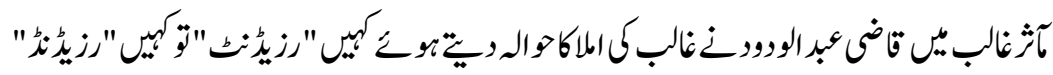

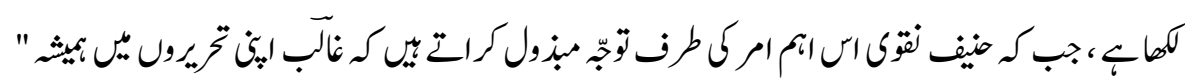

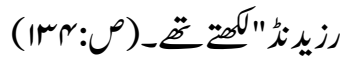

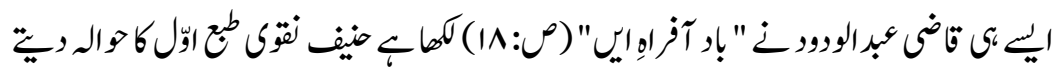

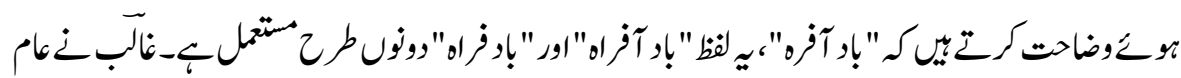

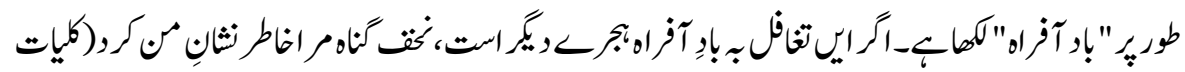

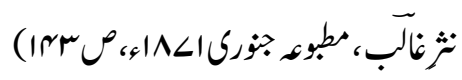

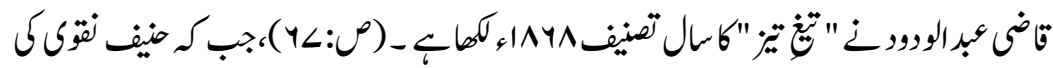

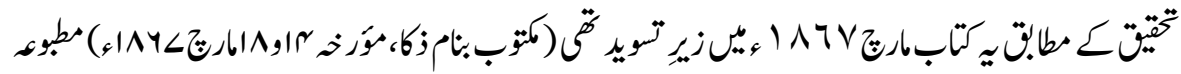

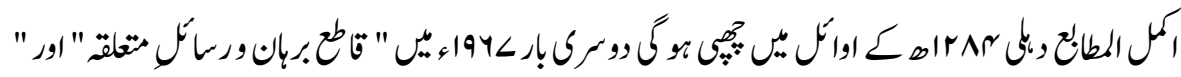

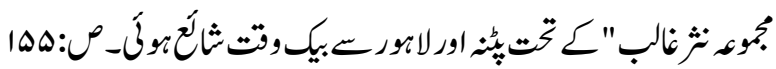

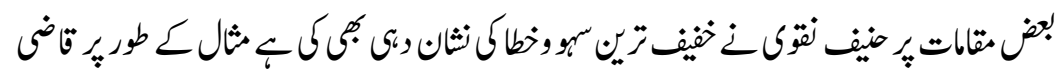

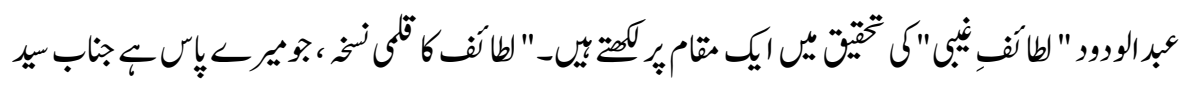

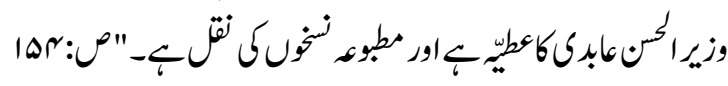

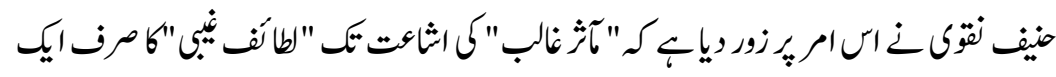

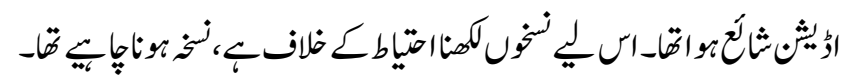


ISSN (Print): 2709-9636 | ISSN (Online): 2709-9644

Volume 2, 2021(Issue III, July to September)

انز تميقي مجل

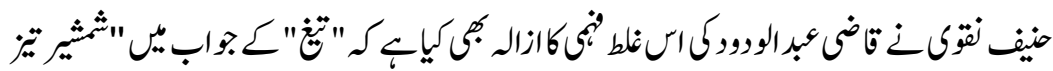

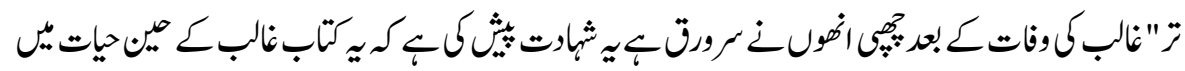

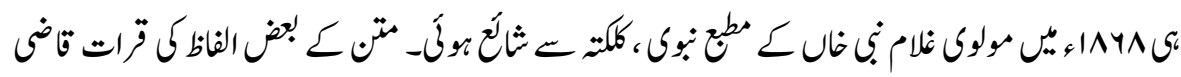

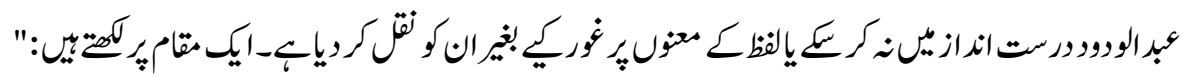

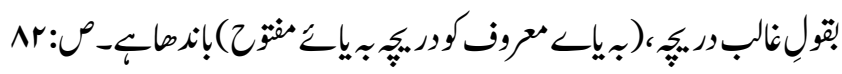

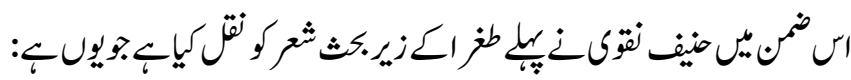

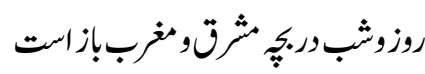

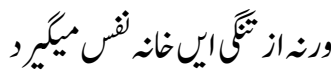

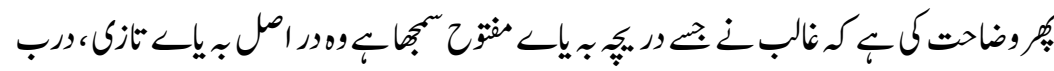

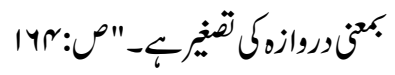

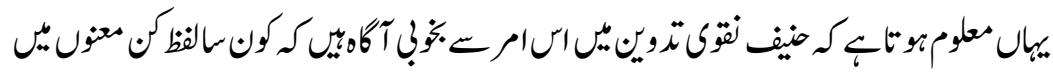

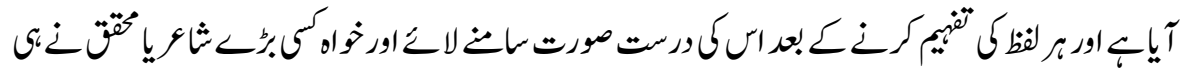

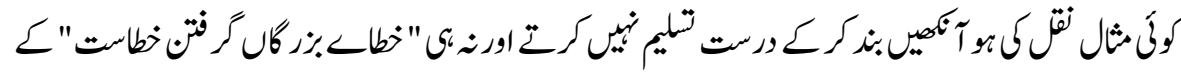

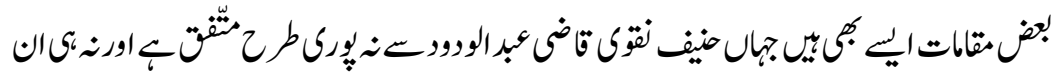

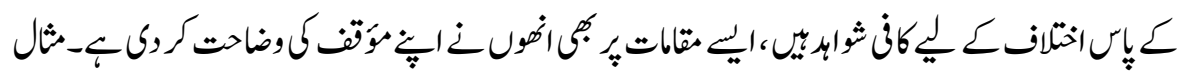

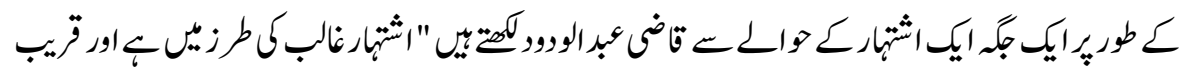

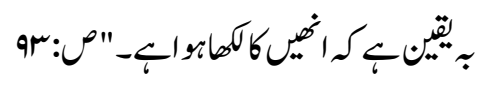

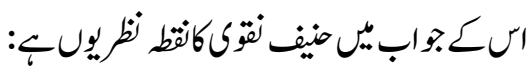

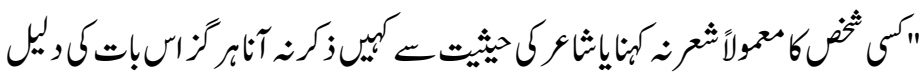

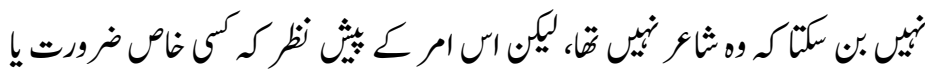

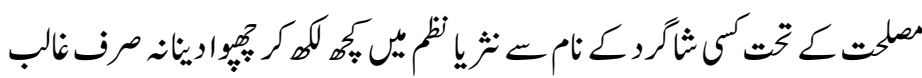


ISSN (Print): 2709-9636 | ISSN (Online): 2709-9644

Volume 2, 2021(Issue III, July to September)

انز تميقي مجل

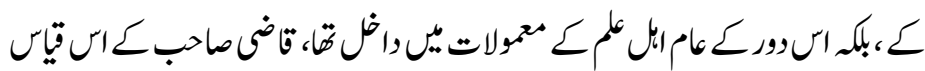

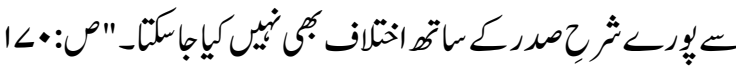

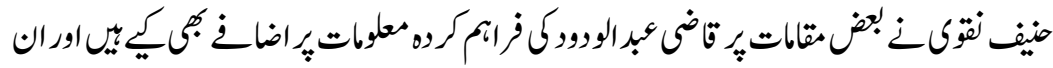

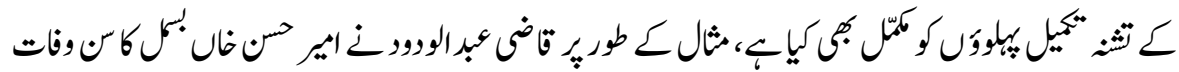
年

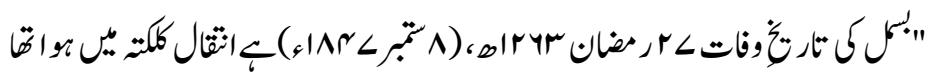

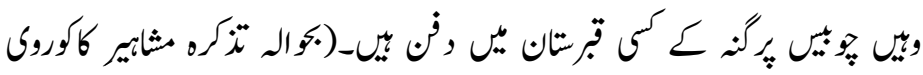

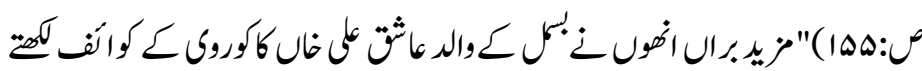

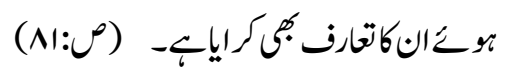

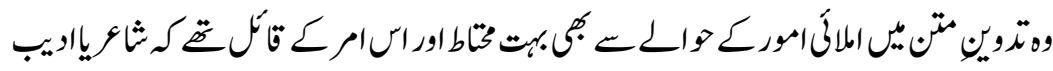

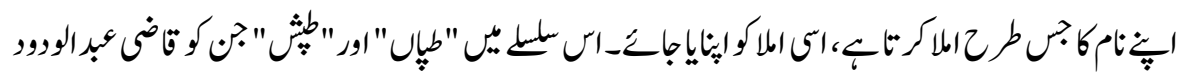

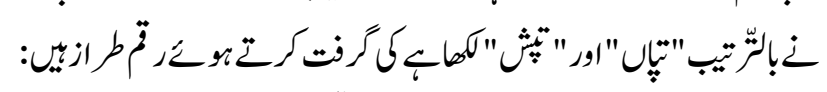

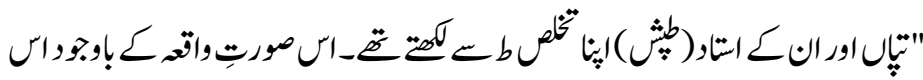

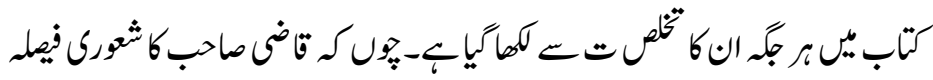

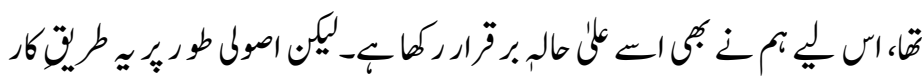

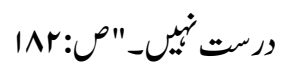

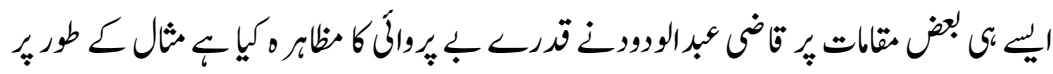

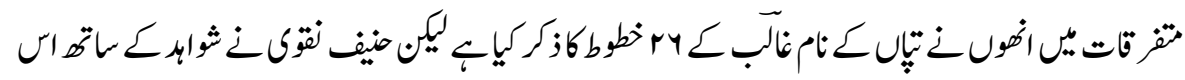

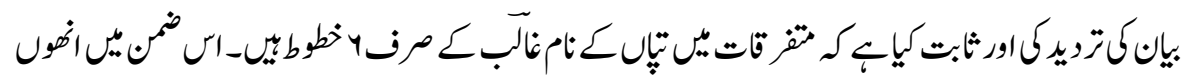

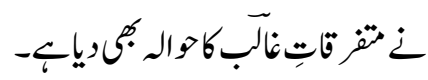

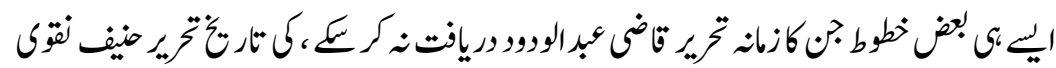

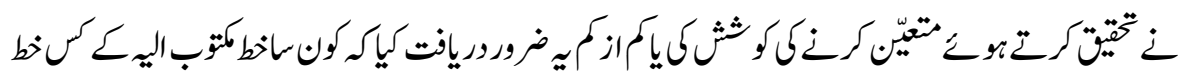

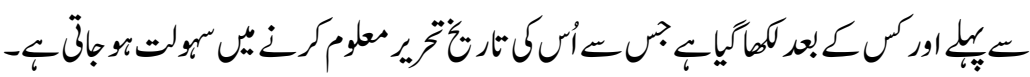


ISSN (Print): 2709-9636 | ISSN (Online): 2709-9644

Volume 2, 2021(Issue III, July to September)

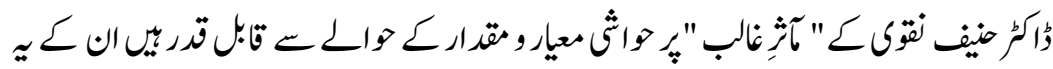

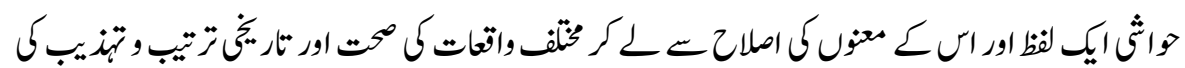

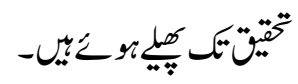

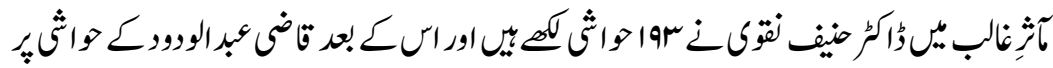

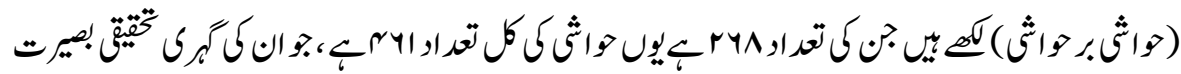

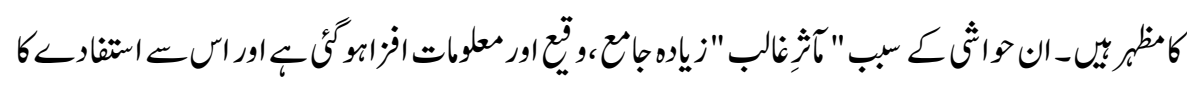

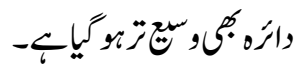

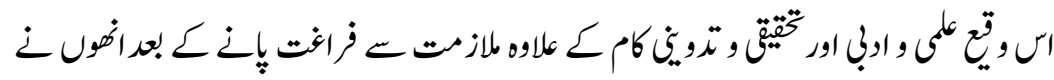

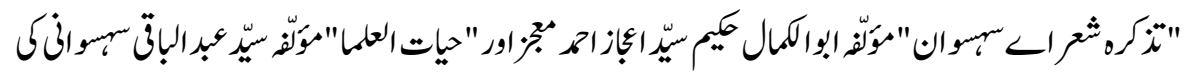

توبينك

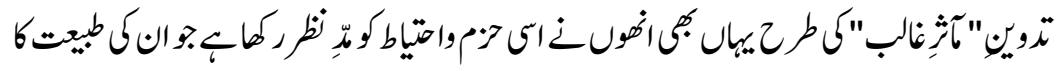

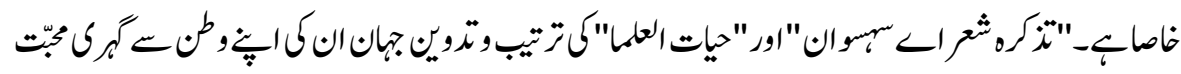

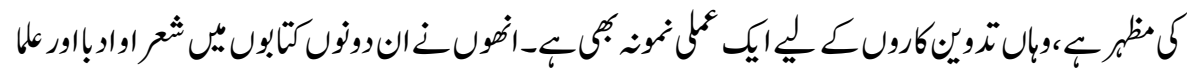

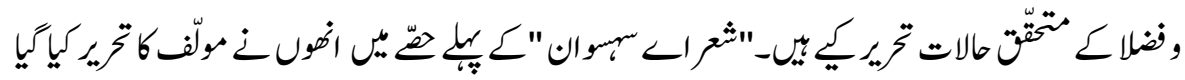

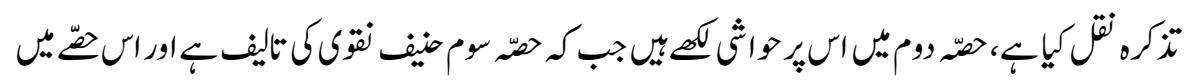

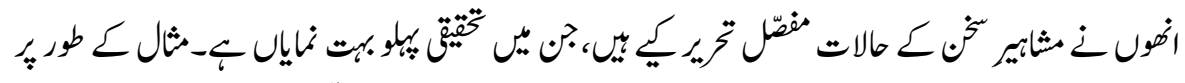

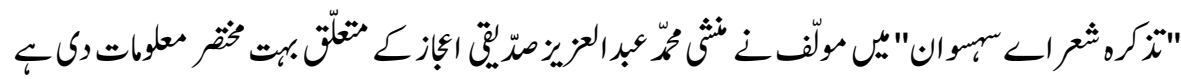

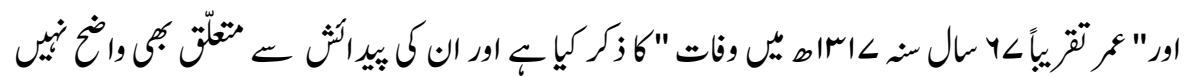

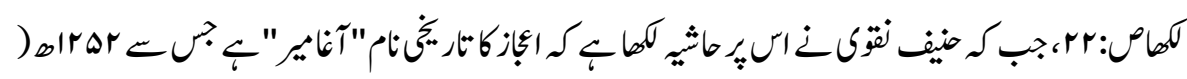

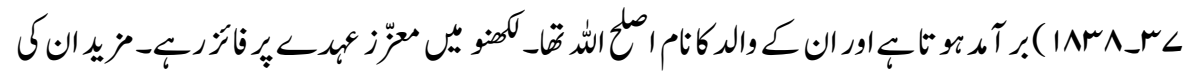

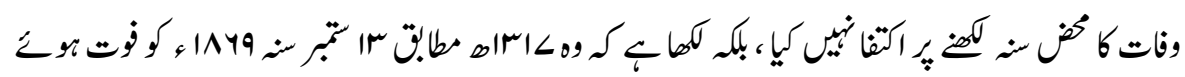

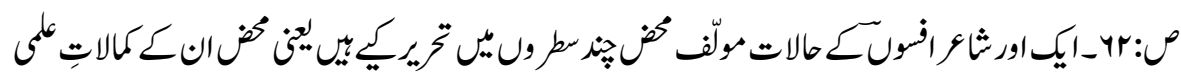

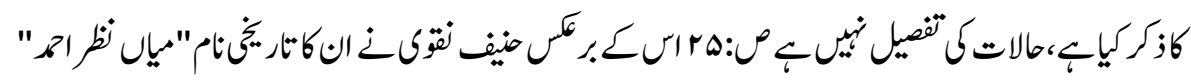


ISSN (Print): 2709-9636 | ISSN (Online): 2709-9644

Volume 2, 2021(Issue III, July to September)

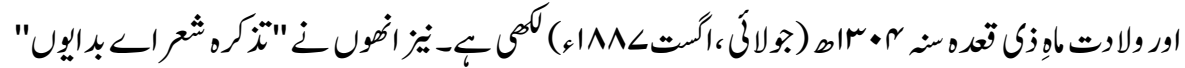

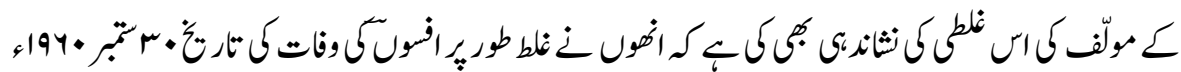

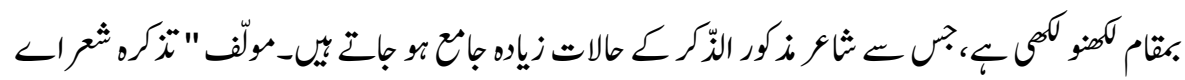

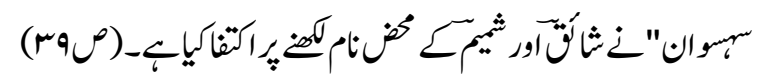

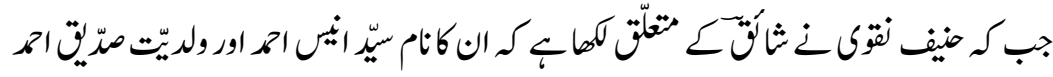

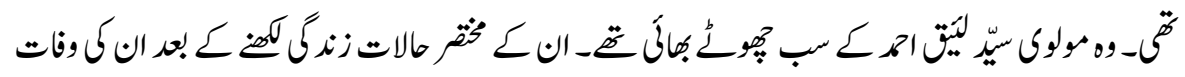

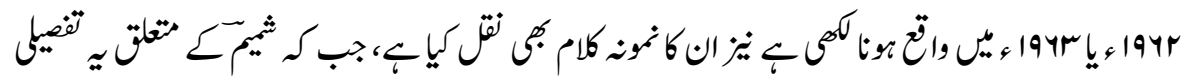

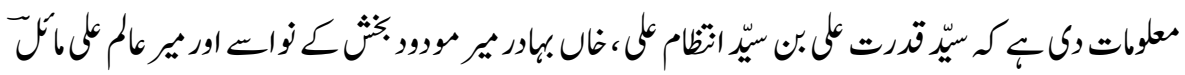

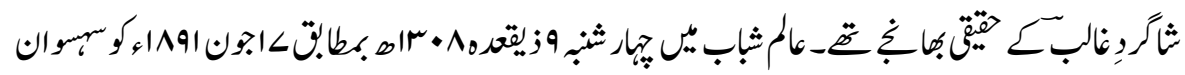

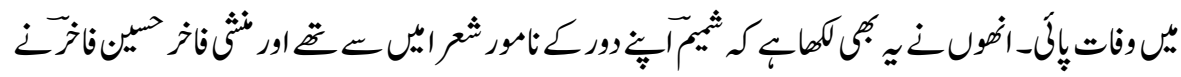

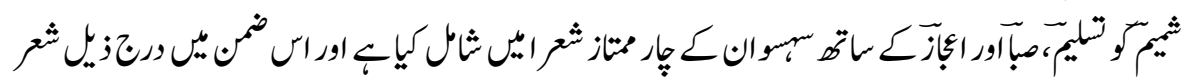

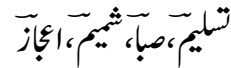

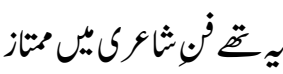

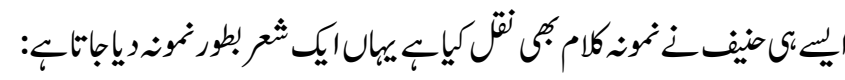

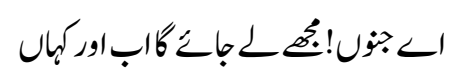

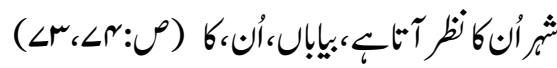

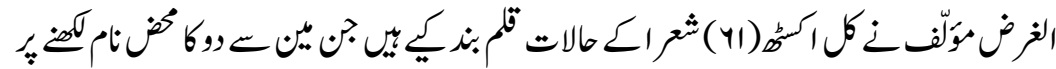

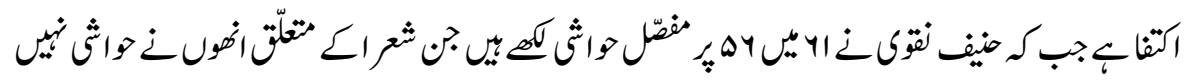

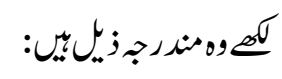

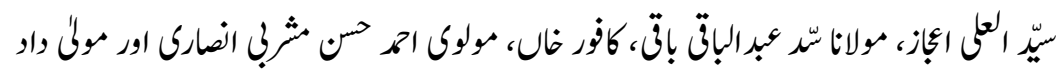

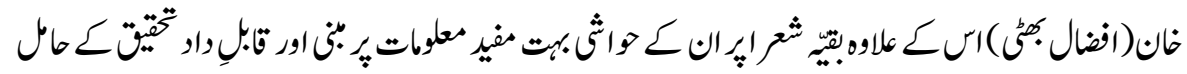


ISSN (Print): 2709-9636 | ISSN (Online): 2709-9644

Volume 2, 2021(Issue III, July to September)

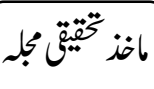

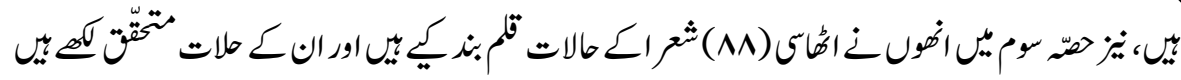

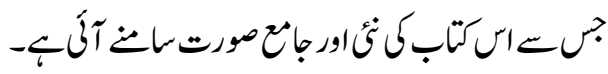

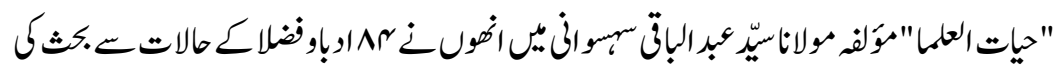

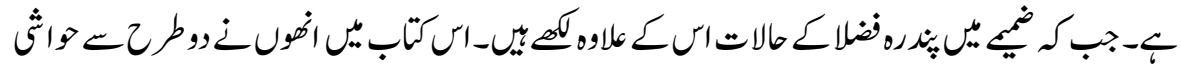

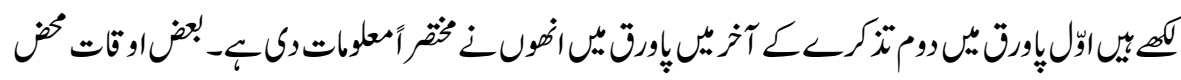

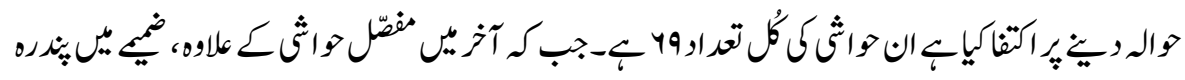

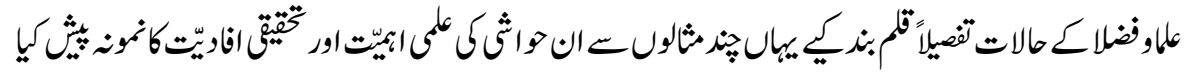

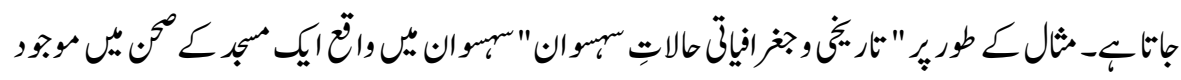

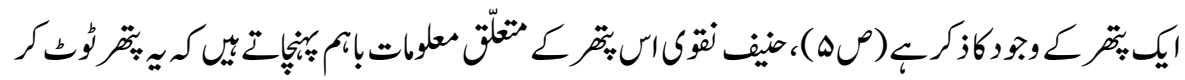

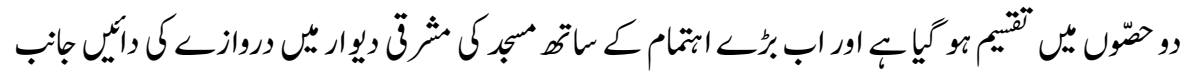

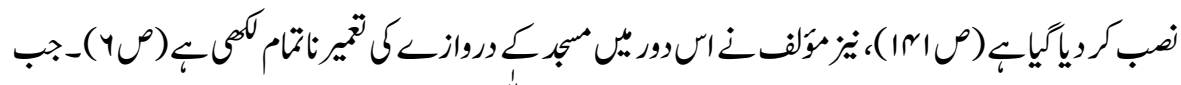

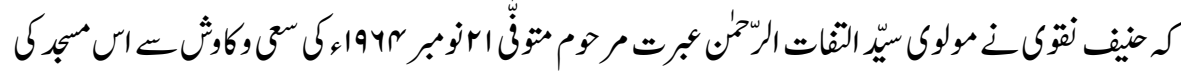

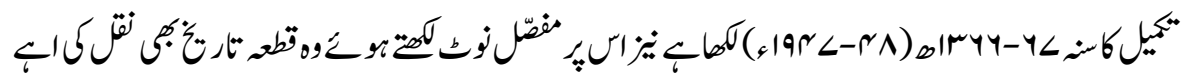

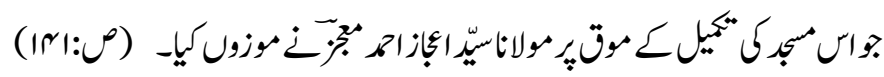

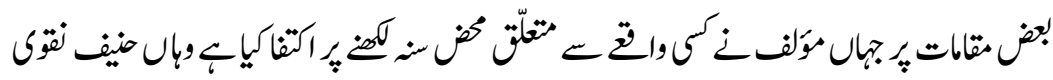

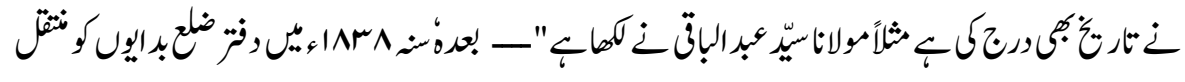

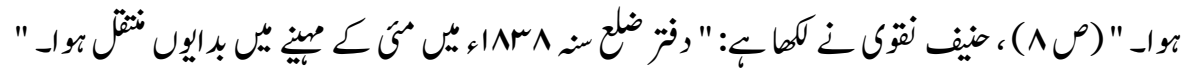

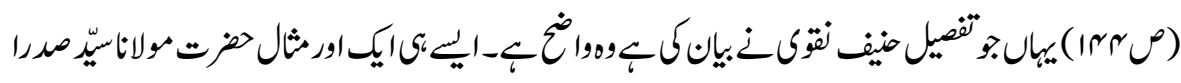

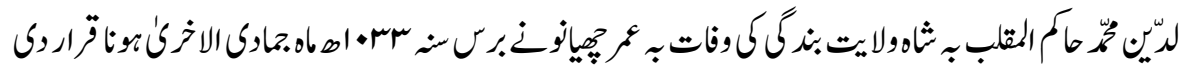

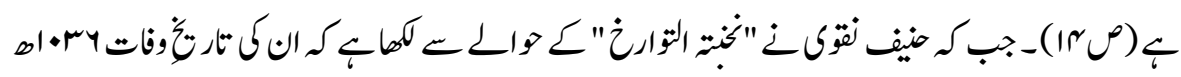

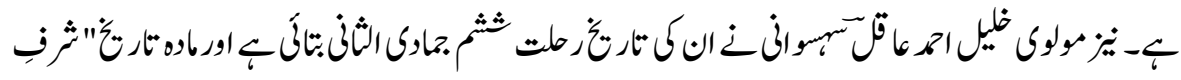

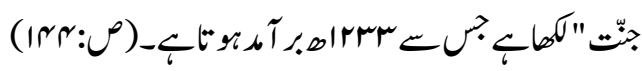


ISSN (Print): 2709-9636 | ISSN (Online): 2709-9644

Volume 2, 2021(Issue III, July to September)

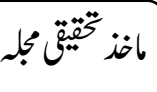

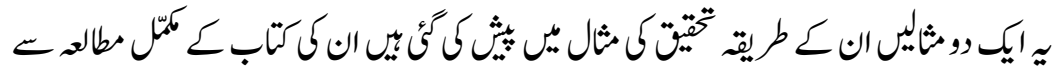

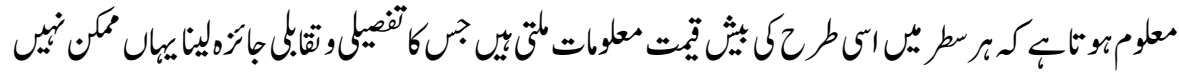

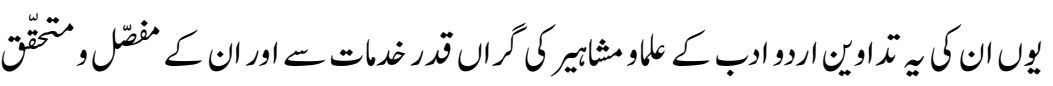
$-4$

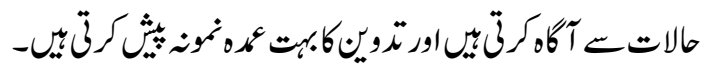

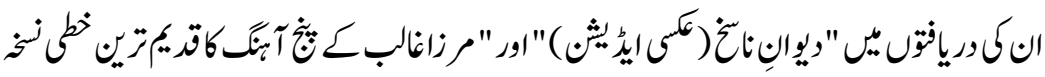

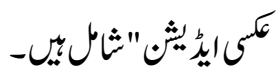

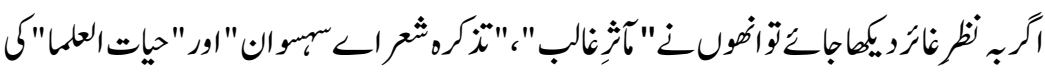

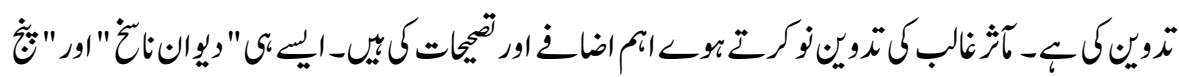

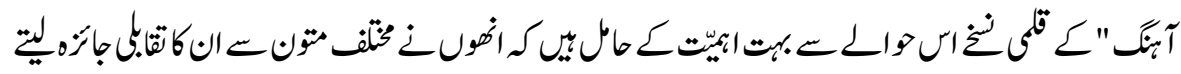

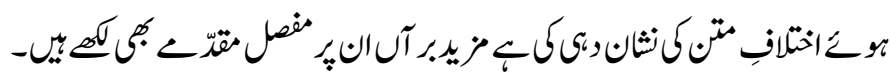

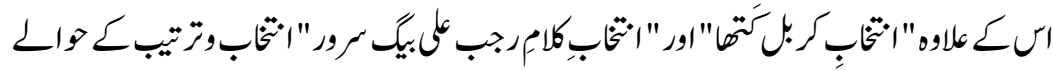

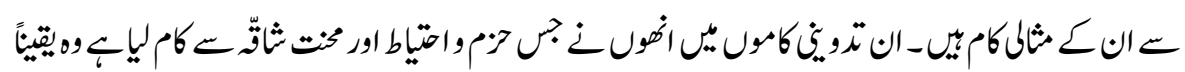

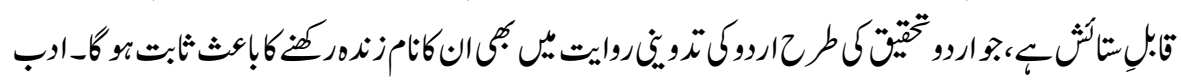

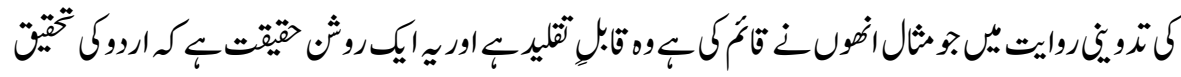

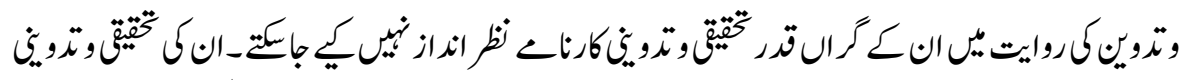

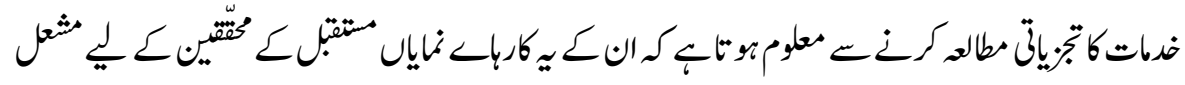

والرجات

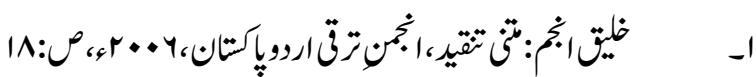

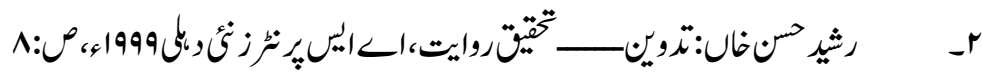
r r 


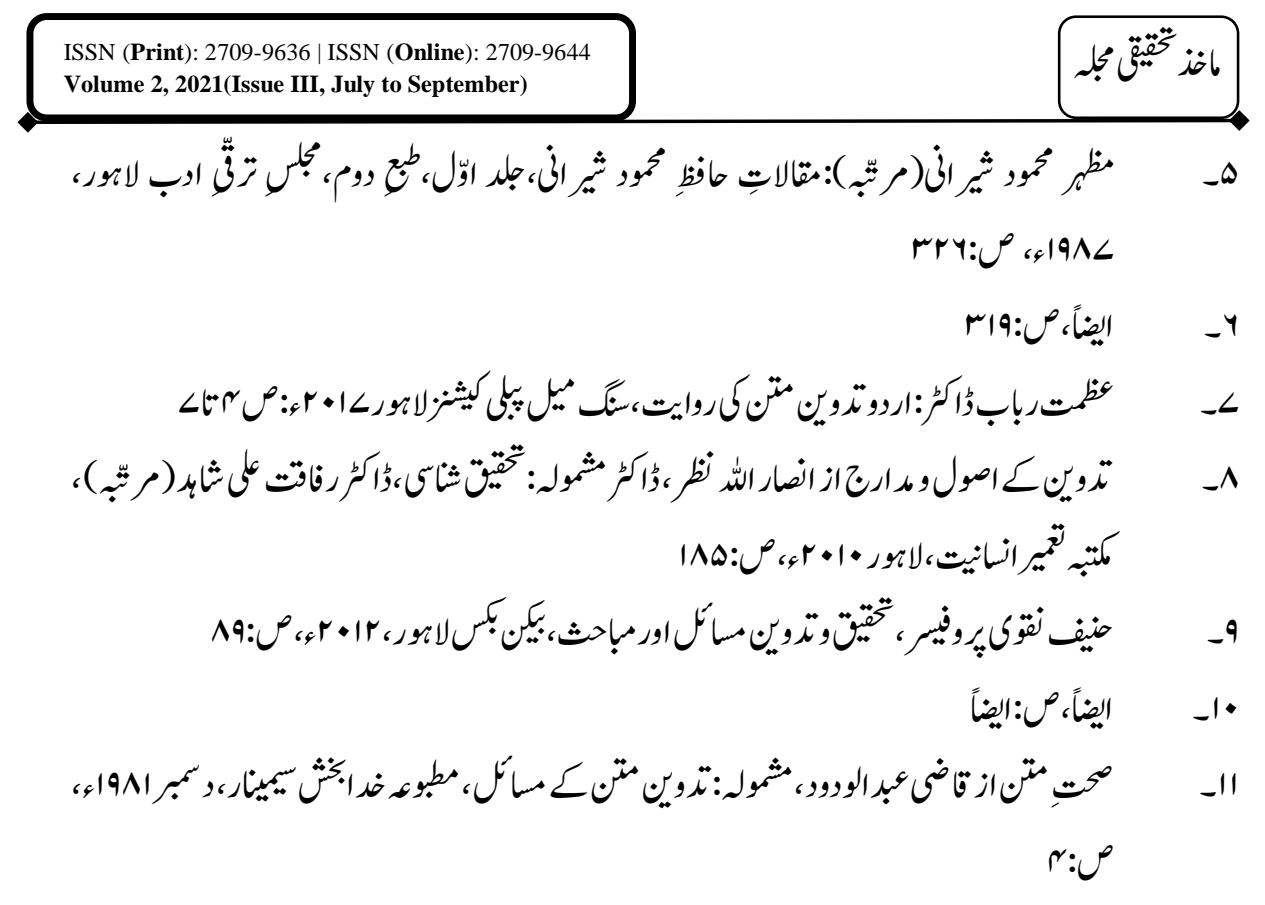

